\title{
Analysis and Application of the Reflection Characteristics of a Simple Retro-reflector
}

\author{
Yong-Beom Jeong, Sung-Hoon Hong, Seung-Gol Lee, and Beom-Hoan $\mathrm{O}^{\dagger}$ \\ School of Information and Communication Engineering, Inha University, Optics and Photonics Elite Research Academy, \\ 253 Younghyun-dong, Nam-ku, Inchon 402-751, Korea
}

(Received June 30, 2014; Revised manuscript August 13, 2014; Accepted August 18, 2014)

\begin{abstract}
Retro-reflectors have been used for a wide range of applications such as traffic safety, special blinds, optical devices, etc. We analyzed the characteristics of the reflected light of a strap retro-reflector as a function of incidence angle. It is expected that various solar control structures may be designed more quantitatively using the characteristic chart we have prepared.
\end{abstract}

Keywords: Geometric optics, Retro reflection, Blind, Retro-reflection characteristic chart OCIS codes: (080.0080) Geometric optics; (080.4035) Mirror system design

\section{1차원적 단순배열구조 재귀반사체의 반사출력광 특성 및 응용 정용범 · 홍성훈 · 이승걸 · 오범환 ${ }^{\dagger}$ \\ 인하대학교 정보통신공학부 광소자 및 $\mathrm{LED}$ 연구실 \\ 우 402-751 인천시 남구 인하로 100}

(2014년 6월 30일 받음, 2014년 8월 13일 수정본 받음, 2014년 8월 18일 게재 확정)

\begin{abstract}
재귀반사체(Retro Reflector)는 그 특별한 기능을 살려 도로 교통안전, 특수 블라인드, 광소자 resonator 등 다양한 분야에서 활 용 영역이 넓어져 가고 있다. 특히 근래에는 '재귀반사구조체'를 창문의 차양 및 채광 구조물로서 도입하여 조명을 스마트화하는 경우도 제시되고 있다. 이에 본 연구는, 태양광 조절용 구조물로서, 띠구조를 1차원적으로 단순배열한 ‘주름판형-재귀반사체’, St-RR(Strap type-Retro Reflector) 구조를 정의하고, 입사각도에 따라 그 반사광의 특성을 분석하였다. 또한, 이 특성 결과를 용이 하게 파악할 수 있도록 시각화한 특성 도표를 고안하였고, 이를 이용하여 각종 태양광 조절 구조물을 보다 정량적으로 설계할 수 있음을 보였다.
\end{abstract}

Keywords: 기하광학, 재귀 반사, 블라인드, 반사 특성 도표

OCIS codes: (080.0080) Geometric optics; (080.4035) Mirror system design

\section{I. 서 론}

재귀반사(Retro reflection)는, 일반적인 단순 거울 반사와 달리, 반사광이 입사광 쪽으로 그대로 되돌아 진행하는 것이 다. 서로 직각으로 놓인 거울면 구조체는, 제한된 조건에서 이런 효과를 얻을 수 있으며, 이러한 직각거울 구조를 미세 하게 반복배열하여 반사면을 구성하면 다양한 용도의 재귀 반사체, RR(Retro Reflector)로서 활용될 수 있다. ${ }^{[1-12]}$ 도로 교통 안전과 관련한 재귀반사체의 쓰임은 이미 매우 범용적 이며, ${ }^{[4]}$ 이미 상당한 관련 지침 ${ }^{[11,}{ }^{12]}$ 도 제정되어 있다. 각종 광소자의 resonator로 사용되는 경우도 있으며, ${ }^{[7]}$ 건축분야에
서도 '베네치안 블라인드' 등의 차양 및 채광구조물의 날개 에 ‘주름판형-재귀반사체', St-RR(Strap type-Retro Reflector)를 도입하고 신제품에 적용시키는 노력이 경주되고 있다. ${ }^{[2, ~ 8-10] ~}$ 블라인드의 각 날개(slat)에, 일반적인 반사면을 사용하는 경 우에는 차양 응용 시에 투시성이 제한되고 반사광의 폐해가 많이 보고되고 있는 반면, St-RR을 도입하여 적절한 설계와 운용조건을 만족하는 경우에는 날개각도를 제한하지 않고도 재귀반사에 의해 직사광선을 차단할 수 있고, 차양과 채광기 능을 우수하게 유지하면서도 동시에 사용자의 가시성을 높 일 수 있을 것으로 기대되고 있다. ${ }^{[8-10]}$ 블라인드의 각 날개에 곡면구조와 재귀반사 구조를 복합적으로 도입하여 이러한

\footnotetext{
${ }^{\dagger}$ E-mail: obh@inha.ac.kr

Color versions of one or more of the figures in this paper are available online.
} 
기대를 이루어 내고자 노력하는 제품사례(제품 참고자료)도 있으나, 광학적 분석은 아직 정량적이지 못하고, 향후의 날개 설계에는 광학특성의 해석적 분석과 이해가 요구된다. $\left.{ }^{[9,} 10\right]$

이제 St-RR의 반사광 특성에 대한 광학적 이해와 분석을 위해, 단순한 1 차원적 배열구조를 해석적 모델로 선택하여 정량화된 논의를 진행한다. 기본적인 단순 재귀반사체로서, 서로 직각배치된 긴 거울띠 주름구조가 반복되는 배열반사 판의 반사특성을 재평가하고, 이 주름구조의 특성각도를 기 울여 반복시키는 배열반사판의 반사특성을 확인하고자 한다. 이렇게 정량화된 반사특성은 '반사특성 도표'를 통하여 이해 하기 용이하게 시각화되었고, '베네치안 블라인드' 등의 날 개 기능성 확장을 비롯한 건물의 차양/채광 구조물 설계에의 응용 가능성을 제시한다.

\section{II. 본 론}

\section{1. 단순구조 재귀반사체의 단위구조}

‘주름판형-재귀반사체', St-RR의 기본 단위구조는 ‘서로 직 각배치된 긴 거울띠’이다. 이를 길이방향에 수직하게 자른 단면은 Fig. 1(a)에 보인 바와 같이 단순한 직각주름 형태가 반복된다. 이제 주름이 반복되는 면을 수평면으로 두고, 빛 의 진행성분이 길이방향으로는 없는 경우에 한정하여 논의 를 진행하면, 길이방향에 수직한 단면이 광학(단)면으로 설 정된다. 그 광학면에서 단위구조체의 주름(거울띠의 폭길이) 이 좌우대칭 되게 배열하는 경우를 고려하면, 거울쌍 단위구 조의 서로 직각배치된 거울띠는 모두 수평면에 45 도의 기울 기를 가지므로, 이를 단위구조의 기울어짐이 없는 기본구조 로 설정하고, 이러한 단순 대칭 구조를 '단순 주름판형 재귀 반사체, SSRR'(Simple Strap-RR)로 정의한다. 이 구조는 수 직입사광에 대해 재귀반사 효율이 $100 \%$ 인 특성을 지닌다. 또한, 이 단위구조가 수평면에 대해 서로 상보적으로 기울어 진 구조를 반복배열하면 거울띠 쌍의 좌우폭이 서로 다른 비 대칭 반복구조가 되고, 이를 '기울인 주름판형 재귀 반사체, ISRR'(Inclined Strap-RR)로 정의한다. (Fig. 1(b)) 이때, 편의

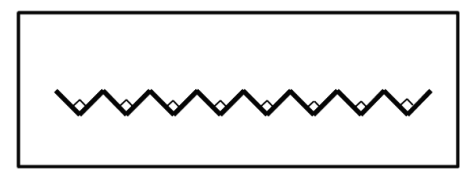

(a)

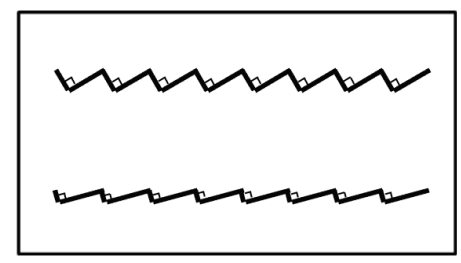

(b)

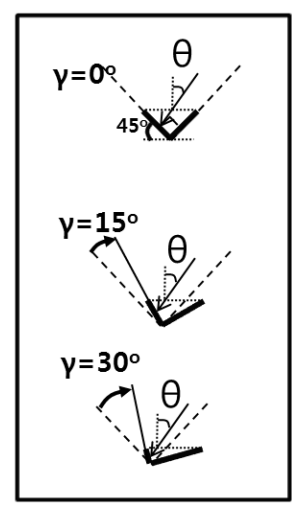

(c)
FIG. 1. Structure of SSRR, ISRR (a) Plain cut of SSRR array, (b) Plain cut of ISRR array, (c) Definition of SSRR, $\theta, \gamma$.
상, 기울인 각도 $\gamma$ 는 Fig. 1(c)의 바닥 꼭지점을 기준으로 좌 우 거울띠 쌍을 시계방향으로 회전하는 것을 양의 방향으로 둔다.

이제, ISRR은 각도 $\gamma$ 에 따라 양쪽 거울띠의 폭이 차이가 심해지게 되므로, 수직입사광에 대해 재귀반사 효율이 $100 \%$ 가 되지 않을 것이다. 또한, 수직이 아닌 특정 입사각도에서 $100 \%$ 재귀반사되는 것을 알 수 있다. 이러한 광입사각은 통 상적으로 '광축'의 개념으로 표현되기도 하며, '완전재귀각 도'의 방향축으로 정의한다. 또한, 거울면을 기준으로 입사각 을 정의하면 혼동을 유발하게 되므로, 본 RR의 광학면과 수 평면, 그리고 수직입사각을 기준으로 입사광의 각도를 정의 하자. 즉, 광학면의 수직선에서 시계 방향으로 기울어진 각 을 양의 입사각 $\theta($ Fig. 1(c))로 정의한다.

\subsection{St-RR(주름판형 재귀반사체)의 특성함수 및 도표}

St-RR의 출력광을 '재귀광', RRL(retro-reflective light)과 '비재귀광', NRL(non-retro reflective light)으로 분류하면, 간 단한 단위구조의 광축 논의에서 보듯이, 재귀반사광 효율이 모든 입사각도에서 항상 $100 \%$ 가 아니며, 나머지 광출력은 비재귀광이 된다. RRL은 입사광이 단위구조체의 양 거울면 에 모두 반사되어 입사방향 벡터의 부호가 바뀐 반사광이다. 즉, 입사광 방향벡터 $\mathrm{A}$ 와 반사광 방향벡터 $\mathrm{B}$ 의 관계는 ${ }^{\mathrm{B}} \mathrm{B}=$ -A'로 표현된다. NRL은 입사광이 단위구조체의 양 거울면 중 한쪽에만 반사하고 그대로 출사되는 경우이며, 해당 거울 면의 법선벡터 $\mathrm{N}$ 과 접선벡터 $\mathrm{T}$ 를 이용하면 ' $0=(\mathrm{A}+\mathrm{B}) * \mathrm{~N}$ ' 혹은 ' $\mathrm{B}=-\mathrm{A}+2(\mathrm{~A} * \mathrm{~T}) \mathrm{T}$ ' 으로 표현될 수 있다.(Fig. 2(a), (b)) 재귀광과 비재귀광의 효율은 단위구조체와 입사각의 간단한 기하학적인 투영 면적비를 고려하여 얻을 수 있고, 비재귀광 의 각도는 상기 벡터 관계식을 이용하여 얻을 수 있다.

여기서 '사용 거울면의 반사율' $=1$ (즉 $100 \%)$ 과 '평행 입사 광’을 가정한 단순한 경우에 대해, 재귀광과 비재귀광의 입 사광 대비 비율이 광입사각 $\theta$ 의 함수로 구해지며, 이를 'St-RR의 특성함수'라고 한다. 이 때, 광축과 같은 각도에서 형성되는 ‘경계각'을 중심으로 빛의 움직임 방향이 둘로 구 분되며, 그러므로 그 두 가지 경우에 대해 각각 특성 함수를 구해야 한다. 이 중 경계각의 왼쪽 부분을 Case 1, Left side

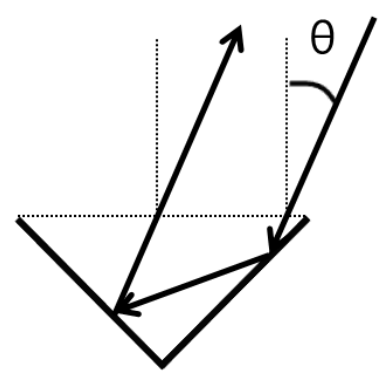

(a)

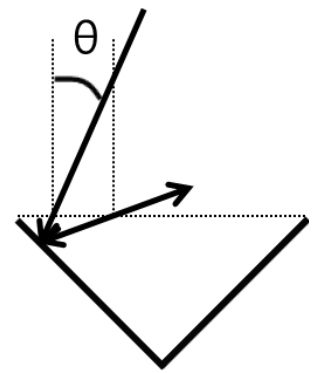

(b)
FIG. 2. RRL and NRL where incident light with same angle, (a) RRL, (b) NRL. 
라고 하고, 이 부분의 특성 함수를 구하는 방법을 그림과 같 이 제시하였다.(Fig. 3) 그림에서 진한 선으로 거울면을, 얇은 실선으로 입사광 및 출사광을, 점선으로 길이요소들을 표현 하는데 필요한 연장선을, 그리고 각도 및 길이요소를 표현한 것을 확인할 수 있다. 이들을 토대로 재귀반사와 비재귀반사 의 영역을 구분짓는 경계선(boundary line)을 파악하고, 이 경계의 좌우에 있는 거울면의 면적(광학면에서의 길이)을 기 하적으로 구하여 각 반사광의 영역 비율을 구할 수 있다. 입 사각의 변화에 따라 기준선의 길이가 바뀌는 것을 고려하여 재귀 반사 길이(RR), 비재귀 반사 길이(NR), 기준선 길이(총 입사 빛의 길이, $\mathrm{L}$ )를 정의하여 규격화하였다. 편의상, 좌측 거울면의 길이를 1 로 하고, 주어진 입사각 $\theta$ 의 경우에 두 번 반사되는 재귀 영역과 한 번 반사로 출사하게 되는 비재귀 영역의 경계부를 그림에 나타내었다. 비재귀 영역의 길이를
$\mathrm{NR}$ 로 표기하였고, 각 길이요소를 광입사각 $\theta$ 와 경사 $\gamma$ 에 대 한 삼각함수 식으로 결정한다. 이 길이요소들은 재귀광 비율 $\mathrm{RR} / \mathrm{L}$ 과, 비재귀광 비율 $\mathrm{NR} / \mathrm{L}$ 로 효율로 변환된다. 이 과정은 Case 2에 대해서도 동일하며 자세한 설명은 부록에서 확인 할 수 있다.

St-RR의 특성함수를 시각화하여 나타낸 특성 도표(Fig. 4.) 는 각을 직관적으로 나타내기 위해 각도기와 같은 반원의 형 태를 하고 있으며, 입사각도 $\theta$ 는 반원의 끝 부분에, 입력광 속 대비 효율의 범위 $0 \sim 1$ 는 왼쪽과 하단 축에 표기해 두었 다. 그래프의 실선은 재귀광, 원 형태의 선은 비재귀광의 출 력각도별 효율변화를 보여주며, 점선은 '1-재귀광'의 입사각 도별 크기를 나타내는 선으로, 출력각도를 나타내는 비재귀 광의 원 형태의 선과는 '거울면'(mirror plane) 대칭적이다. 단위구조체의 양쪽 거울이 직각인 관계로 반사거울면과 짝

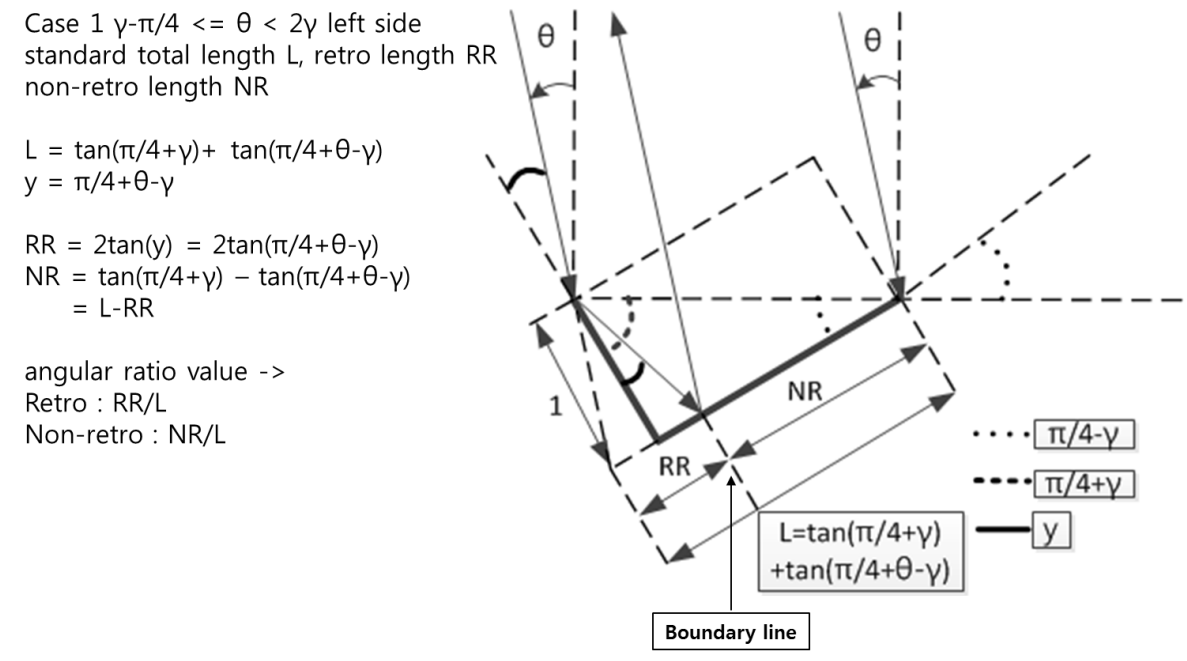

FIG. 3. Partition of each reflective region for RR and NR (Case 1, left side).

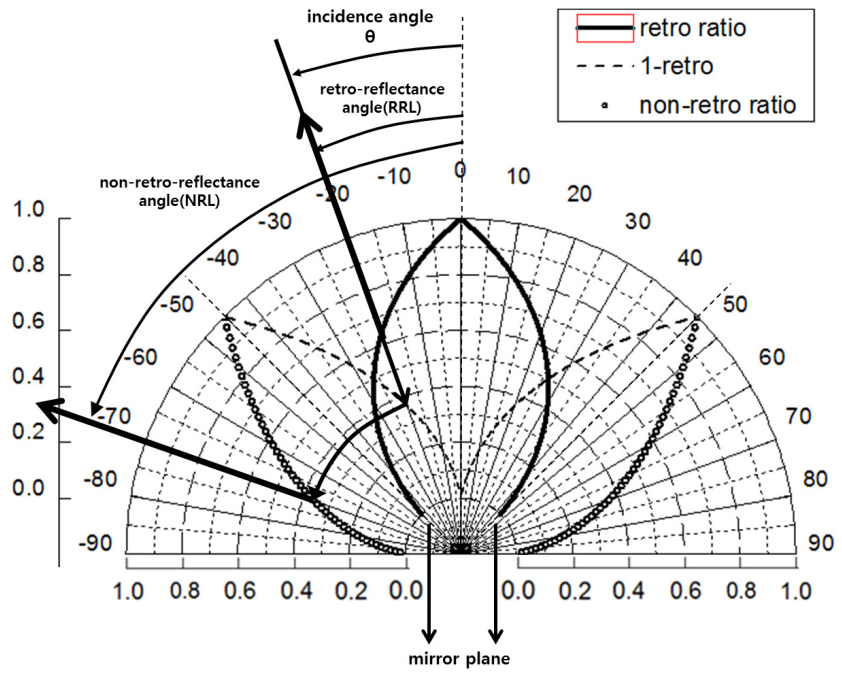

(a)

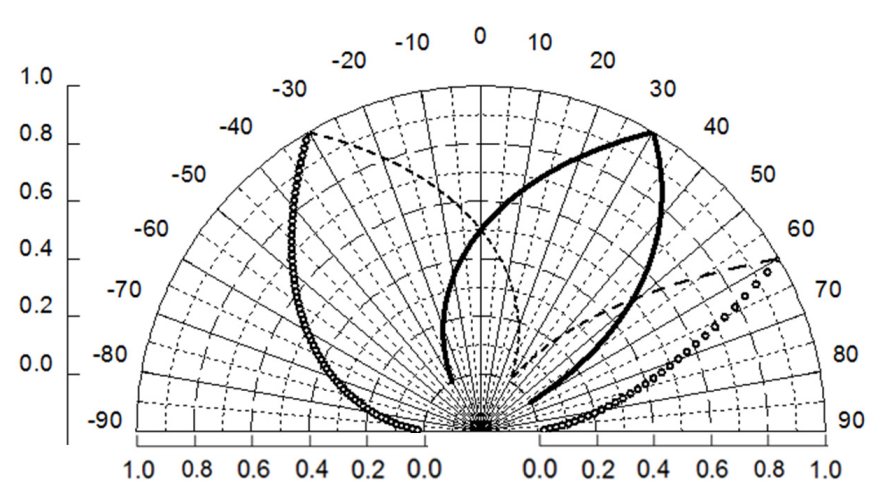

(b)

FIG. 4. St-RR's Characteristic chart (a) SSRR, (b) ISRR $\left(\gamma=15^{\circ}\right)$. 
을 이루는 거울면 방향이 대칭축 각도와 같다. 이 대칭축 각 도는 재귀반사가 가능한 영역의 경계인 '한계각도'이기도 하 며, 기울임 각도 $\gamma$ 에 의하여 기울어진 ISRR의 경우에도 그 대로 적용된다. 실제적으로 도표를 볼 때, 재귀광의 출력각 은 입사각과 같으므로, 입사각 $\theta$ 에 따른 재귀광 비율은 동일 각도의 실선을 읽으면 되며, 비재귀광은 해당 입사각의 점선 이 효율이고, 대칭축에 대해 대칭이동한 각도로 출사된 다.(Fig. 4(a) 참조) 결과적으로, 그래프를 사용하여 대칭이동 하는 분석방식은 비재귀광의 거동을 직관적으로 이해하여 활용할 수 있게 하며, 재귀광의 각도별 효율변화와 기울임에 따른 특성변화의 거동을 직관적으로 나타내주고 있다.

이제 St-RR 특성 도표의 또 다른 장점은 재귀반사 가능영 역의 가시화이다. 재귀반사 가능영역은 항상 기본 단위구조 체의 두 거울면 쌍이 이루고 있는 각도 영역과 동일하다. 예 를 들어, $\operatorname{SSRR}(\gamma=0)$ 의 경우에 재귀반사 가능영역은 $-45^{\circ}$ 에 서 $45^{\circ}$ 까지 총 $90^{\circ}$ 이며, ISRR에서는 $\gamma$ 가 커짐에 따라 시계방 향으로 기울며 변한다. 이를 식으로 표현하면, $\gamma-45^{\circ}<\theta<\gamma$ $+45^{\circ}$ 의 90 도 영역이다. 기울임 각도 $\gamma$ 가 커짐에 따라 광축 $(100 \%$ 재귀반사 각도) 또한 시계 방향으로 회전하는데, 이 광축 각도는 $\theta=\gamma$ 가 아니고 $\theta=2 \gamma$ 가 되며, 이는 거울면 쌍의 좌우길이가 달라지면서 투영면적비 상보특성의 변화 때문에 발생한다. 실제로 $\gamma$ 만큼 기울어진 경우에도 배열구조 상의 전제 조건이 없어서 좌우 거울면 쌍의 좌우길이가 같다면 반 사체의 수평면이 전체적으로 기울어진 것과 같고, 이때의 광 축 각도는 단순히 $\gamma$ 가 될 것이다. 재귀반사광은 광축각도 $(\theta$ $=2 \gamma)$ 에서 1 로 가장 크며, 좌/우 거울면의 각도에 다다르면 0 이 된다. 이는 $\gamma=0$ 일때는 대칭적이나, $\gamma$ 가 커짐에 따라 비대 칭적으로 변한다. 비재귀광은 앞서 설명된 것처럼, 양 쪽 거 울면 중 하나에 반사되었으나 다른 거울면에 반사되지 못하 여 외부로 빠져나가는 광으로서, $\gamma-45^{\circ}<\theta<\gamma+45^{\circ}$ 의 바깥 영역으로 반사된다. 이러한 출사각도의 특이성을 블라인드 날개 등의 조명구조체에 적절히 활용하면, 건물 내부 방향으 로 빛을 들이도록 설계함으로써 채광의 지능화도 가능하므 로 다음 절에 기술한다.

\section{3. 특성 도표의 채광설계 적용 및 논의}

차양 및 채광용 베네치안 블라인드는 여러 개의 날개로 이 루어져 있으며, 외부의 직사광을 차단하기 위해서는 태양 고 도에 따라 날개의 각도를 회전하여 단순히 가리거나 그림자 를 활용하게 된다. 이때, 날개의 기울기가 증가하면서 사용 자의 시야를 가려 가시율이 저하되며, 외부의 이웃 사용자에 게 반사광으로 눈부심이 유발되는 등의 단점이 있다. 이러한 문제를 해결하고자 날개 형상을 곡선화 하거나, 1 차원적 재 귀 반사체를 부분 삽입하는 방법 등으로 특정 태양 고도의 범위에서 날개를 기울이지 않은 채 차양하는 방법도 이미 제 안되고 있으나, 해석적 설계기술은 아직 제안되지 않고 있다. 앞선 절에서 제시한 St-RR의 특성 도표는 태양고도에 따른 출력광의 거동을 직관화하였기에 이를 사용하면, 투시율을 개선한 차양 뿐 아니라 실내 채광에 목적을 두고 날개를 설
계하는 것이 용이하다. 즉, 태양광이 오른편 창문에 비치는 경우에 그 고도를 입사각으로 두면, 실내는 좌측부에 있으므 로, 기울임 각도 $\gamma$ 를 적절히 증가하면 광축을 적절한 고도에 두도록 설계할 수 있고, 입사 태양광의 일부는 비재귀광 출력 을 통해 실내의 적절한 각도로 채광도 가능하게 된다. 또한 $\gamma$ 를 키울수록 원 형태의 선의 비재귀광의 크기가 증가하여, 높 은 조도를 얻을 수 있다. 이와 같이 목적에 맞는 $\gamma$ 를 선택하 여, 실내로 비재귀광을 채광하면 천장에 위치시킨 저(低) 확 산 반사면 등을 이용하여 실내 조도 개선에 도움을 주므로, 친환경적 건축기술에도 크게 기여하게 될 것으로 판단된다.

\section{III. 결 론}

주름판형-재귀반사체(St-RR)의 단위구조 반사체의 기울임 각도 $\gamma$ 에 따라 재귀광/비재귀광 특성을 파악하고 그 거동을 직관화하는 특성 도표를 고안하였다. $\gamma$ 가 커짐에 따라 완전 재귀효율을 갖는 광축 각도는 $\theta=2 \gamma$ 로 이동하였으며, 재귀광 및 비재귀광의 출력 효율 및 각도 영역의 변화 거동을 확인 하여 그래프로 나타내고, 이를 활용하는 구조체 설계 기법을 제안하였다.

재귀반사체를 적용하는 광학구조물의 설계에 본 St-RR의 특성 도표가 널리 활용될 수 있을 것으로 기대하며, 베네치 안 블라인드의 날개 설계의 경우, 채광 및 차양을 지능화하 는 친환경적 블라인드 시스템의 최적 설계도 가능한 것으로 기대한다.

\section{감사의 글}

본 연구는 '중소기업융복합기술개발사업'와 지식경제부 및 정보통신산업진흥원 '대학 IT 연구센터 육성지원 사업'의 연 구결과로 수행되었음.

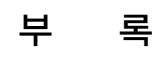

특정각도로 입사광이 주어질 때, 재귀광과 비재귀광의 입 사광 대비 비율이 '특성함수'이며, 이는 기본적으로 '투영면 적(광학면에서는 길이)의 비'이다. 광축이 수직방향인 대칭 구조는 'SSRR'이라고 정의되었고, 일반적으로 단위구조를 각도 $\gamma$ 만큼 기울인 구조인 'ISRR'의 경우를 Appendix. Fig. 1 에 보였다. Appendix. Fig. 1에 보인 바와 같이 광축을 $(\theta=2 \gamma)$ 기준으로 경우가 나뉘는 것을 감안하여 Case 1 과 2 로 구분 하여 각 길이를 구하면 된다. 수직선 방향의 입사광을 '입사 각 무을 로 두면, 입사각이 $2 \gamma$ 보다 작을 때를 case 1 , 클 때를 case 2로 한다. 이는 Appendix. Fig. 1에 나타내었다.

Case1 "좌": 좌측 거울면의 각도 $\left(-45^{\circ}+\gamma\right)$ 부터 $2 \gamma$ 각도까지, 즉 $-45^{\circ}+\gamma<\theta<2 \gamma$

Case2 "우": $2 \gamma$ 각도부터 우측 거울면의 각도 $\left(45^{\circ}+\gamma\right)$ 까지, 즉 $2 \gamma<\theta<45^{\circ}+\gamma$ 
이제, 각 경우에 대하여, 입사각과 반사각을 고려하여 양측 거울면에 두 번 반사하게 되는 재귀반사와 한쪽 거울면에만 반사하게 되는 비재귀반사의 영역을 구분짓는 '경계선(boundary line)'을 파악하고, 이 경계의 좌우에 있는 거울면의 면적(광 학면에서의 길이)를 기하적으로 구하여 재귀광, 비재귀광에 대한 반사영역 비율을 구한다. 입사각에 따라 기준선의 길이 도 바뀌는 것을 감안하여 재귀 반사 길이(RR) 및 비재귀 반 사 길이(NR), 총 입사 빛의 길이(L)를 정의하였다. Appendix. Fig. 2 의 Case 1 의 경우에, RR과 NR의 “경계"는 St-RR의 우 측 거울에 존재한다. 이 때, “경계선”의 좌측 거울면으로 입

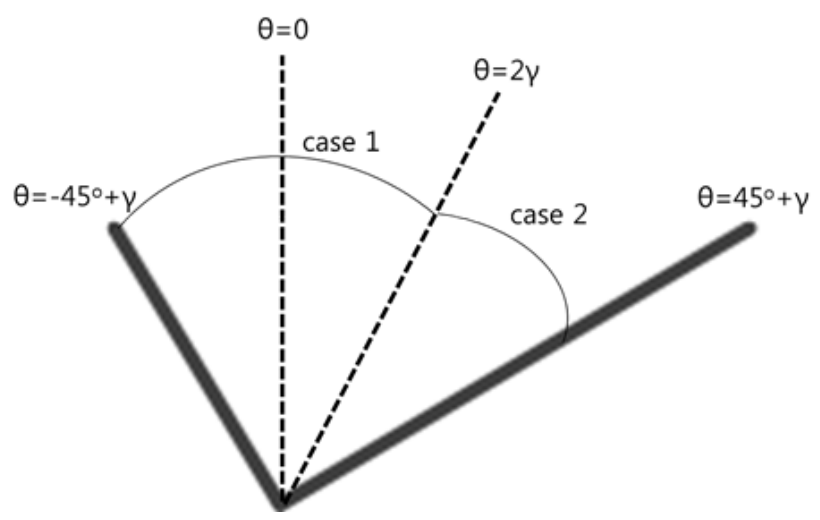

Appendix. FIG. 1. (a) Case categorization.

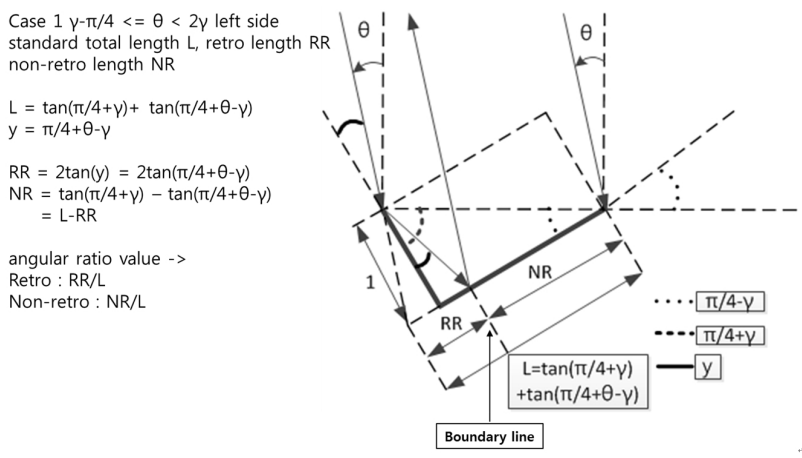

Appendix. FIG. 2. (a) Partition of each reflective region for RR and NR (Case 1, left side).

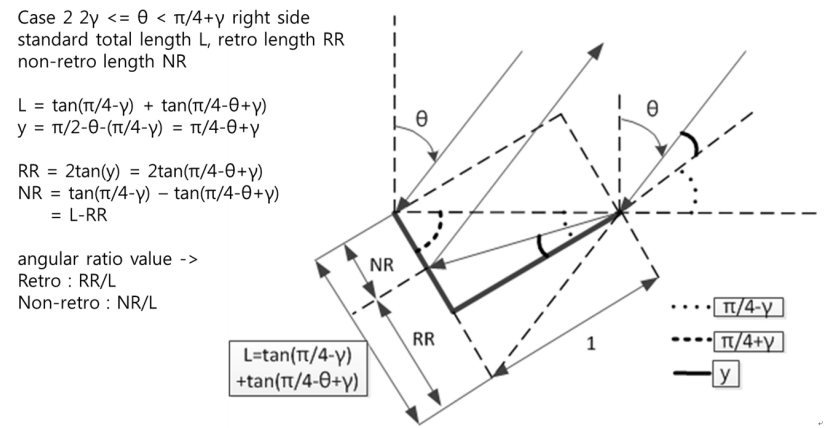

Appendix. FIG. 2. (b) Partition of each reflective region for RR and NR (Case 2, right side).
사하는 광flux는 모두 재귀반사, "경계선"의 오른쪽 거울면 으로 입사하는 광flux는 모두 비재귀반사를 하게된다. 이제, 각 거울면과 입사각과 관련된 연장선을 그리고, 길이를 정규 화하기 위해, 좌측 거울면의 길이를 1 로 두고 각 $\mathrm{RR}, \mathrm{NR}, \mathrm{L}$ 의 길이를 입사각 $\theta, \gamma$ 에 대한 삼각함수 식으로 결정한다. 이 길이는 각각 재귀광 비율 $\mathrm{RR} / \mathrm{L}$, 비재귀광 비율 $\mathrm{NR} / \mathrm{L}$ 로

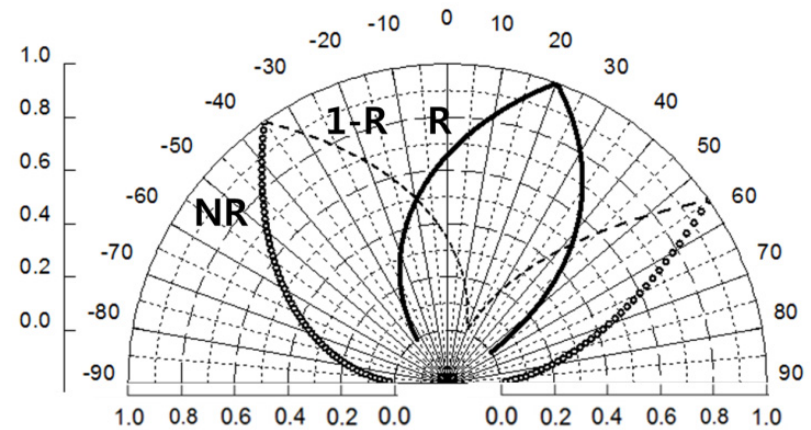

(a)

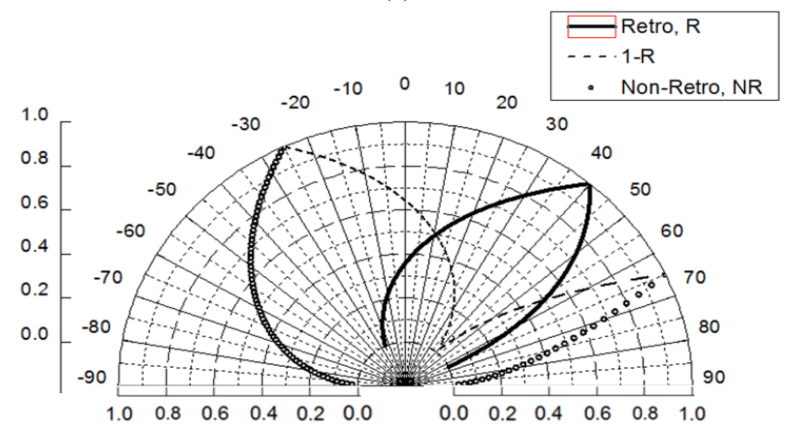

(b)

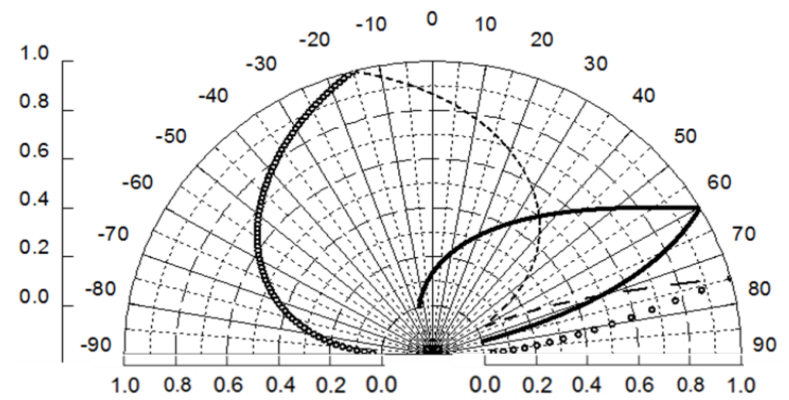

(c)

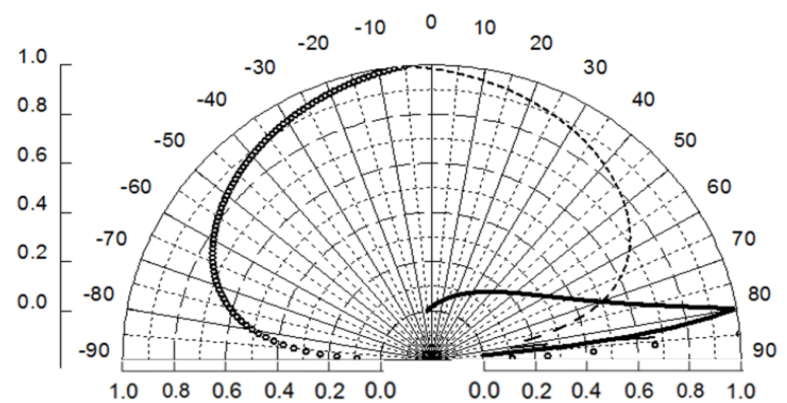

(d)

Appendix. FIG. 3. (a) $\sim\left(\right.$ d) Characteristic Chart of ISRR $\left(\gamma=10^{\circ}\right.$, $20^{\circ}, 30^{\circ}, 40^{\circ}$ ). 
효율로 변환한다. 이 과정은 Case 2에 대해서도 동일하다. 그림 3에는 기울임 각도를 바꾸어가며 얻어낸 특성도표를 차례로 제시하였다.((a) $\operatorname{SSRR}\left(\gamma=0^{\circ}\right)$, (b) (i) $\operatorname{ISRR}\left(\gamma=5^{\circ} \sim 40^{\circ}\right.$, $5^{\circ}$ 간격)

\section{References}

1. J.-S. You and B.-K. Kang, "A study on applicable methods and design process of daylighting," Journal of Architectural Institute of Korea 20, 391-394 (2000).

2. A. Tsangrassoulis, "A review of innovative daylighting systems," Advances in Building Energy Research 2, 33-56 (2008).

3. A. D. Machin, D. Naylor, S. J. Harrison, and P. H. Oosthuizen, "Experimental study of free convection at an indoor glazing surface with a venetian blind," HVAC\&R Research, vol. 4, no. 2, Toronto, Ontario, Canada (1998).

4. K. Choi, S. Lee, I. Yun, and Y. Yi, "A methodology development for estimating the retroreflectivity of pavement markings and traffic guide signs using digital images," Journal of the Korean Society of Civil Engineers 34, 185-194 (2014).
5. Susumu TACHI, "Telexistence and retro-reflective projection technology(RPT)," in Proc. the 5th Virtual Reality International Conference (Laval Virtual, France, 2003), pp. 69/1-69/9.

6. C. M. Collier, X. Jin, J. F. Holzman, and J. Cheng, "Omnidirectional characteristics of composite retroreflectors," Journal of Optics A: Pure and Applied Optics 11, 085404 (10pp), BC.V1V 1V7, Canada (2009).

7. Z. E. Bagdasarov, "Investigation of the characteristics of formation of the angular distribution of laser radiation in resonators with retroreflecting mirrors," Sov. J. Quantum Electron. 11, Nov. Moscow, Russia (1981).

8. H. Koster, Dynamic Daylighting Architecture: Basics, Systems, Projects (Birkhauser Publishers, Basel, Switzerland, 2004).

9. H. Koster, "Toothed daylight blinds," United States Patent, US 6,845,805 B1, Frankfurt am Main, Germany (2005).

10. H. Koster, "Sun protection installation comprising sun protection lamellae having a toothed upper side," United States Patent, US 6,367,937 B2, Frankfurt, Germany (2002).

11. Traffic Safety Signal Setting \& Management Manual, Korean National Police Agency, 10-15, Korea (2011).

12. Traffic Road Signal Setting \& Management Manual, Korean National Police Agency, 19-23, Korea (2012). 